\title{
1 Reductive Capacity Measurement of Waste Forms for Secondary Radioactive Wastes
}

\author{
Wooyong Um ${ }^{1,2, *}$, Jung-seok Yang ${ }^{3}$, and R. Jeffrey Serne ${ }^{1}$, and Joseph H. Westsik Jr. ${ }^{1}$ \\ ${ }^{1}$ Energy and Environment Directorate, Pacific Northwestern National Laboratory (PNNL), 902 \\ Battelle Blvd., P7-54, Richland, WA 99354, USA \\ ${ }^{2}$ Division of Advanced Nuclear Engineering, Pohang University of Science and Technology \\ (POSTECH), 77 Chongam-lo, Nam-gu, Pohang 790-784, Republic of Korea \\ ${ }^{3}$ Environmental Research Group, Korea Institute of Science \& Technology (KIST), 679 \\ Saimdang-ro, Gangneung 210-340, Republic of Korea \\ *Corresponding author \\ Submitted to Journal of Nuclear Materials \\ E-mail: Wooyong.um@pnnl.gov; Phone: +1-509-372-6227; Fax: +1-509-376-1638
}

25

26

27

28

29

30

31

32

33

34

35

36

37

38

39 
ABSTRACT

41 The reductive capacities of dry ingredients and final solid waste forms were measured using both

42 the $\mathrm{Cr}(\mathrm{VI})$ and $\mathrm{Ce}(\mathrm{IV})$ methods and the results were compared. Blast furnace slag (BFS),

43 sodium sulfide, $\mathrm{SnF}_{2}$, and $\mathrm{SnCl}_{2}$ used as dry ingredients to make various waste forms showed

44 significantly higher reductive capacities compared to other ingredients regardless of which

45 method was used. Although the BFS exhibits appreciable reductive capacity, it requires greater

46 amounts of time to fully react. In almost all cases, the Ce(IV) method yielded larger reductive

47 capacity values than those from the $\mathrm{Cr}(\mathrm{VI})$ method and can be used as an upper bound for the

48 reductive capacity of the dry ingredients and waste forms, because the Ce(IV) method subjects

49 the solids to a strong acid (low $\mathrm{pH}$ ) condition that dissolves much more of the solids. Because

50 the $\mathrm{Cr}(\mathrm{VI})$ method relies on a neutral $\mathrm{pH}$ condition, the $\mathrm{Cr}(\mathrm{VI})$ method can be used to estimate

51 primarily the waste form surface-related and readily dissolvable reductive capacity. However,

52 the $\mathrm{Cr}(\mathrm{VI})$ method does not measure the total reductive capacity of the waste form, the long-term

53 reductive capacity afforded by very slowly dissolving solids, or the reductive capacity present in

54 the interior pores and internal locations of the solids.

58 Key words: reductive capacity; waste form; blast furnace slag; cast stone; geopolymer; 59 ceramicrete 


\section{Introduction}

Large volumes of radioactive wastes were produced at the U.S. Department of Energy's

(DOE's) Hanford Site in southeastern Washington State during the Cold War era and most of the radioactive waste is presently stored in 177 underground Hanford storage tanks [1]. The radioactive waste generated at the Hanford Site is present in fuel reprocessing wastes, which are awaiting retrieval, treatment, immobilization, and permanent disposal. After the wastes are retrieved from the storage tanks, current disposal plans call for separation of the waste into two fractions: a high-level waste (HLW) and a low-activity waste (LAW) stream, both which will be treated, vitrified, and disposed of separately. The Hanford Tank Waste Treatment and Immobilization Plant (WTP) is under construction to treat the radioactive wastes and immobilize them in a glass waste form. The HLW stream will be vitrified and stored at Hanford until a deep-geologic repository is built to receive this defense radioactive waste as well as commercial spent nuclear fuel. In addition, at least a portion of $(\sim 35 \%)$ the LAW stream will be converted into a borosilicate glass waste form, which will be disposed of in a shallow burial facility at the Hanford Site, the Integrated Disposal Facility (IDF) [2]. Even with careful engineering controls, melter off-gas scrubbers and returned to the melter. However, some of the volatile radionuclides are expected to be lost and become part of the secondary waste stream from the vitrification process [1]. A solidification treatment unit (STU) is being constructed at the effluent treatment facility (ETF) on the Hanford Site. The ETF processes low-level radioactive, mixed wastewaters, and secondary radioactive liquid wastes generated during various Hanford Site operations and in the future may process the secondary wastes from the WTP. Because of the cost considerations 
83 and volatility issues, the volatile secondary radioactive wastes need to be solidified in a lowtemperature-based waste form [3-5].

Low-temperature waste solidification processes commonly use reductants that are inherently present in the dry blend or are added to improve the retention of redox-sensitive metal/metalloid and radioactive contaminants such as $\mathrm{Cr}$, Se, ${ }^{129} \mathrm{I},{ }^{99} \mathrm{Tc}$, and ${ }^{238} \mathrm{U}$ in the solid waste forms. These redox-sensitive contaminants are generally much less soluble when present in their reduced valence states in solutions or solids. Their ability to adsorb or co-precipitate with solidification compounds and soils/sediments is much better in the reduced forms than in the oxidized forms. Thus, when chemically reduced, the mobility of these contaminants is significantly decreased when disposed in subsurface environments. Therefore, measuring the reductive capacity of waste forms, as well as the dry ingredients used to make waste forms, is a key task needed to project the long-term performance of the waste forms after they are placed in the subsurface environment. Shallow land-burial repositories typically have partially watersaturated, mildly-oxidizing, and near-neutral $\mathrm{pH}$ conditions. The influx of $\mathrm{O}_{2}$-saturated fresh pore waters and $\mathrm{O}_{2}$ in the air that partially fills the unsaturated pores will over time push the redox status of the repository toward oxidizing conditions by consuming any reducing agents present in the waste forms and other repository materials. The weathering of the emplaced waste forms and the time required for the natural environmental oxidizing conditions to consume any reducing agents can be estimated by measuring the reducing capacity (i.e., meq of electrons/kg of material) of the emplaced materials.

At least two widely used measurement techniques have been described in the literature for determining reductive capacity in materials such as fly ash, blast furnace slag (BFS), and native sediments, etc. [6,7]. Simply stated, both procedures define reductive capacity as the 
amount of an oxidant that can be reduced by a testing material when sufficient time is given that the reaction proceeds to its maximum extent or equilibrium condition. The technique described by Angus and Glasser (1985) uses cerium (IV) as the oxidant, while the Lee and Batchelor (2003) method uses $\mathrm{Cr}(\mathrm{VI})$ as the oxidant. Because there are significant differences [a factor of $\sim 22$, with the Ce(IV)-based technique yielding the larger value [8] for materials such as BFS, which is a commonly used material in low-temperature cementitious waste forms. Thus, both procedures should be tested and the results need be compared to understand the range in reductive capacity for materials. The objectives of this study were to test these two methods and to measure the reductive capacity of several different waste forms and their dry ingredients as well as liquid simulants used to prepare different waste forms.

\section{Materials and Methods}

Four different waste forms [Cast Stone, DuraLith, fluidized bed steam reformer (FBSR), and Ceramicrete] prepared with or without ${ }^{99} \mathrm{Tc}$ using different simulant compositions, as well as dry ingredients, were tested for reductive capacity measurements. More details for waste form preparation are found in previous reports $[9,10]$.

\subsection{Waste Simulant and Waste Form Details}

Briefly speaking, the Cast Stone is a cementitious waste form that was developed to solidify the low-activity and secondary waste that will be generated by the operation of the WTP at the Hanford Site $[11,12]$. Cast Stone consists of a mixture of Class-F fly ash, Grade-120 BFS, and Type-I/II Portland cement. For the Cast Stone waste form, eight different simulants were spiked with Tc or spiked with Re as a surrogate for Tc. The eight liquid simulants were the same simulants as used in the Cast Stone Phase-II tests (S1-2, -4, -6, -8, and -10 M Na; S2-2 M Na; 
S3-2 M Na; and S4-2 M Na), which are described in detail in Sundaram et al. (2011) [10].

129 Simulant S1 solutions with 4, 6, 8, and $10 \mathrm{M} \mathrm{Na}$ were prepared with increased amounts

130 (multiplied by 2, 3, 4, and 5) of each constituent found in the S1-2 M Na simulant (Table 1) to 131 make the target simulants. The other four simulant compositions (S1-2 M Na, S2-2 M Na, S3-2

$132 \mathrm{M} \mathrm{Na}$, and S4-2 M Na) are the same as simulants S1, S2, S3, and S4 described in Table 1. Both

133 Tc-spiked and Re-spiked Cast Stone samples were prepared to measure reductive capacity.

Geopolymers, also known as alkali-activated aluminosilicate binders, form through the reaction of aluminosilicate materials, such as clay or fly ash, in a caustic solution. When the

136 reactions proceed at near-ambient temperature, polymerization forms amorphous to semi-

137 crystalline aluminosilicate networks [13]. A specific geopolymer known as "DuraLith" was

138 included to test the reductive capacity measurement for Hanford WTP secondary wastes [14].

139 DuraLith is composed of three components — an activator, a binder, and an enhancer [3,9]. The

140 activator is a solution of sodium hydroxide and/or potassium hydroxide with a rapidly dissolving

141 form of silica, such as silica fume (also known as microsilica) or fly ash. The binder is a mixture

142 of meta-kaolinite, BFS, fly ash, or other additives. The binder and activator are the two main

143 components that yield the geopolymer material. The enhancers are essentially getter material

144 like $\mathrm{SnF}_{2}$. Both Tc-free and Tc-spiked DuraLith waste forms were prepared with the four

145 different simulants (S1, S2, S3, and S4) and measured for reductive capacity. Each of the dry

146 ingredients used in preparing DuraLith (i.e., fumed silica, meta-kaolinite, river sand, silver

147 zeolite, BFS, sodium sulfide hydrate $\left[\mathrm{Na}_{2} \mathrm{~S} \cdot 9 \mathrm{H}_{2} \mathrm{O}\right]$, and $\mathrm{SnF}_{2}$ ) also were analyzed to obtain their 148 individual reductive capacities. 
151 FBSR granules $\mathrm{r}$ were prepared using a WTP secondary-waste simulant injected into a

152 laboratory-scale steam reforming apparatus, and the reformer product was screened $(<1.0 \mathrm{~mm})$.

153 The FBSR-GEO-7 monoliths (2-in.-diameter by 4-in.-long cylinders) also were prepared by

154 mixing the FBSR solids with a geopolymer binder. The Geo-7 geopolymer was created by

155 mixing fly ash with sodium silicate and sodium hydroxide with an FBSR product waste loading 156 of $65.2 \%$. More details regarding the two FBSR samples can be found in Pires et al. (2011) [15].

157 Ceramicrete is fabricated by an acid/base reaction of calcined magnesium oxide and 158 mono potassium phosphate, which forms a slurry when mixed with water that sets into a hard 159 ceramic in a few hours based on Eq. (1) $[16,17]$.

$$
\mathrm{MgO}+\mathrm{KH}_{2} \mathrm{PO}_{4}+5 \mathrm{H}_{2} \mathrm{O} \rightarrow \mathrm{MgKPO}_{4} \cdot 6 \mathrm{H}_{2} \mathrm{O}
$$

162 Ceramicrete waste form, only S1 simulant spiked with Tc was prepared. This Ceramicrete final 163 waste form and all its dry ingredients $\left(\mathrm{SnCl}_{2}\right.$, fly ash [Type C], silver zeolite, $\mathrm{MgO}$, and $\left.\mathrm{KH}_{2} \mathrm{PO}_{4}\right)$ 164 were also analyzed for reductive capacity.

\subsection{Particle size analysis}

The measurement of the reductive capacity of the dry materials and final waste forms is

167 sensitive to their grain-size distribution, because particle size affects the rate at which the redox 168 reactions occur in the test solutions. Therefore, all the dry materials and final waste forms were 169 ground to less than a $1.0-\mathrm{mm}$ size fraction and sieved before reductive capacity measurements.

170 Particle-size characterization was also done with a Mastersizer 2000 (Malvern Instruments, Inc.,

171 Southborough, Massachusetts) particle-size analyzer with a Hydro G wet dispersion accessory 
172 (equipped with a continuously variable and independent pump, stirrer, and ultrasound). The

173 Mastersizer has a nominal size measurement range of $0.02 \mu \mathrm{m}$ to $2000 \mu \mathrm{m}$. The actual range is

174 dependent on the accessory used as well as the properties of the solids being analyzed. When

175 coupled with the Hydro $G$ wet dispersion accessory, the nominal measuring range is $0.02 \mu \mathrm{m}$ to

$1762000 \mu \mathrm{m}$ dependent on material density. A performance check of the particle-size analyzer was

177 performed with a particle-size standard traceable to the National Institute of Standards and

178 Technology before any particle-size analysis was undertaken. Small aliquots of the samples

179 ( 0.2 to $1 \mathrm{~g}$ for dry powders) were diluted in degassed DIW in the Hydro G dispersion unit with

180 the pump and stirrer speeds set at $2500 \mathrm{rpm}$ and $1000 \mathrm{rpm}$, respectively, for 60 seconds before

181 making the particle-size measurements. The total volume of the dispersion unit was $\sim 800 \mathrm{~mL}$.

182 Appropriate dilutions were determined by the amount of light passing through the diluted

183 material (obscuration), which was measured by the particle-size analyzer. Samples were

184 analyzed, initially without sonication and then during sonication $(100 \%, 20 \mathrm{~W})$ after an initial

185 sonication period of 60 seconds. Duplicate samples were measured to confirm the mixing and

186 sub-sampling technique to make sure that a representative particle-size distribution (PSD) of the

187 material could be obtained.

\subsection{Reductive capacity measurement}

The Ce(IV) method for measuring reductive capacity described by Kaplan et al. (2005)

190 and Augus and Glasser (1985) [6,8] was slightly modified. Generally, two different

191 concentrations of $\mathrm{Ce}(\mathrm{IV})$ stock solution $(10 \mathrm{mM}$ and $40 \mathrm{mM})$ were prepared in $10 \% \mathrm{H}_{2} \mathrm{SO}_{4}$

192 solution using $\left(\mathrm{NH}_{4}\right)_{4} \mathrm{Ce}\left(\mathrm{SO}_{4}\right)_{4} \cdot 2 \mathrm{H}_{2} \mathrm{O}$ (Sigma-Aldrich). Based on results of preliminary tests, if

193 the reductive capacity of the sample was higher than $100 \mathrm{meq} / \mathrm{kg}$, the $40-\mathrm{mM} \mathrm{Ce}(\mathrm{IV})$ stock 
194 solution was used. For samples with less than $100 \mathrm{meq} / \mathrm{kg}$ reductive capacity, the $10-\mathrm{mM} \mathrm{Ce}(\mathrm{IV})$

195 stock solution was used. The procedure then used $0.5 \mathrm{~g}$ of testing sample ( $<1 \mathrm{~mm}$ size fraction)

196 mixed with $15 \mathrm{~mL}$ of the appropriate $\mathrm{Ce}(\mathrm{IV})$ stock solution in a $20-\mathrm{mL}$ vial. Immediately after

197 mixing, the vial was tightly capped and placed on a platform shaker to mix completely at room

198 temperature $\left(23 \pm 2^{\circ} \mathrm{C}\right)$ for 1 day. To determine the effect of mixing time, the reaction time also

199 was varied between 1 hour and 7 days for certain samples (BFS and Cast Stone) to test for

200 kinetic effects before measuring the reduction capacity of other materials. The solution was then

201 filtered with a $0.45-\mu \mathrm{m}$ syringe filter (Whatman) after the target reaction time. Then $0.05 \mathrm{~mL}$ of

202 Ferroine solution $\left[0.025 \mathrm{M} \mathrm{Fe}(\mathrm{o}-\text { phenanthroline })_{3}{ }^{2+}\right.$, Fluka] was mixed with $5 \mathrm{~mL}$ of the filtrate,

203 and the final solution was titrated using a Metrohm titrator that dispensed $20 \mathrm{mM}$ of ammonium

204 ferrous sulfate prepared in $4 \% \mathrm{H}_{2} \mathrm{SO}_{4}$ solution until the solution developed and retained a lilac

205 color. Before the measurement of reductive capacities, the concentration of ammonium ferrous

206 sulfate solution was initially calibrated with standard Ce(IV) solution (1 M, Sigma-Aldrich).

207 The reductive capacity was calculated by determining the difference between the oxidizing

208 equivalents in $\mathrm{Ce}(\mathrm{IV})$ solution [meq $\mathrm{Ce}(\mathrm{IV})]$ and the reducing equivalents of $\mathrm{Fe}(\mathrm{II})$ needed to

209 neutralize excess $\mathrm{Ce}(\mathrm{IV})$ after reaction with the sample [meq $\mathrm{Fe}(\mathrm{II})]$. The final reductive

210 capacity per gram was calculated by dividing the reductive capacity (meq) by the mass of sample

$211(\mathrm{~g})$.

The Cr(VI) reduction capacity procedure developed by Lee and Batchelor (2003) [7] also

213 was modified. The $\mathrm{Cr}(\mathrm{VI})$ stock solutions $(10 \mathrm{mM}$ or $30 \mathrm{mM})$ were prepared with $\mathrm{K}_{2} \mathrm{CrO}_{4}$

214 (Sigma-Aldrich) in 10-mM $\mathrm{NaHCO}_{3}$ solutions. The $\mathrm{Cr}(\mathrm{VI})$ solutions were then purged with $\mathrm{N}_{2}$

215 gas for 2 hours, and the stock solution then was introduced into an anoxic chamber (Coy

216 Laboratory Products Inc.) containing a mixed gas atmosphere $\left(4 \% \mathrm{H}_{2}\right.$ and $\left.96 \% \mathrm{~N}_{2}\right)$. One-gram 
217 samples of the waste form or dry ingredients were placed in 20-mL quartz vials and then

218 introduced into the anoxic chamber. The sample vial and $\mathrm{Cr}(\mathrm{VI})$ stock solution were kept in the

219 anoxic chamber for 2 days to allow any air present in the containers to diffuse out before use.

220 After the 2-day air-purging period, $10 \mathrm{~mL}$ of the $\mathrm{Cr}(\mathrm{VI})$ stock solution was mixed into the

221 sample vial, and the $\mathrm{pH}$ of the suspension was adjusted to $7 \pm 1$ by adding a $1-\mathrm{M} \mathrm{NaOH}$ or

222 1- $\mathrm{M} \mathrm{H}_{2} \mathrm{SO}_{4}$ solution. The vials were tightly capped, removed from the chamber, placed on a

223 platform shaker, and allowed to mix at room temperature $\left(23 \pm 2^{\circ} \mathrm{C}\right)$ for 7 days. To determine the

224 effect of shaking time, some of the test vials with BFS and Cast Stone samples were allowed to

225 shake for varying times, ranging from 1 hour to 7 days. After mixing, the vial was transferred

226 back into the anoxic chamber, and $0.142 \mathrm{~g}$ of sodium sulfate was added. The vials were re-

227 sealed, removed from the chamber, and shaken on the platform shaker for one more day. This

228 was done to remove any potentially adsorbed $\mathrm{Cr}(\mathrm{VI})$ from the materials being tested so that the

229 final $\mathrm{Cr}$ measurement in solution truly reflected all the $\mathrm{Cr}(\mathrm{VI})$ that was reduced and precipitated

230 as $\mathrm{Cr}(\mathrm{III})$. The final supernatant was filtered with a $0.45-\mu \mathrm{m}$ syringe filter, and the concentration

231 of $\mathrm{Cr}(\mathrm{VI})$ in the final filtrate was determined by a titration method. One $\mathrm{mL}$ of the filtrate was

232 mixed with $1 \mathrm{~mL}$ of the $\mathrm{H}_{2} \mathrm{SO}_{4}$ solution (1:1 ratio) and $0.05 \mathrm{~mL}$ of Ferroine solution, as used for

$233 \mathrm{Ce}(\mathrm{IV})$ method. The resultant solution was titrated with $20 \mathrm{mM}$ or $10 \mathrm{mM}$ ammonium ferrous

234 sulfate solution, which was prepared in $4 \% \mathrm{H}_{2} \mathrm{SO}_{4}$ solution, until the solution became and

235 remained lilac in color. The final reductive capacity was calculated by determining the

236 difference between the oxidizing equivalents in $\mathrm{Cr}(\mathrm{VI})$ and the reducing equivalents of $\mathrm{Fe}(\mathrm{II})$ as

237 described above in Ce(IV) method. 


\section{Results and Discussion}

\section{1 . Particle size analysis}

The reductive capacities of the waste forms and their individual dry ingredients were measured separately by using both redox pairs, $\mathrm{Ce}(\mathrm{IV}) / \mathrm{Ce}(\mathrm{III})$ or $\mathrm{Cr}(\mathrm{VI}) / \mathrm{Cr}(\mathrm{III})$, with back titration of excess oxidant with $\mathrm{Fe}(\mathrm{II})$. In both the $\mathrm{Ce}(\mathrm{IV})$ and $\mathrm{Cr}(\mathrm{VI})$ methods, the test materials reach an end point based on the following reactions:

$$
\begin{gathered}
\mathrm{Fe}(\mathrm{II})+\mathrm{Ce}(\mathrm{IV}) \rightarrow \mathrm{Fe}(\mathrm{III})+\mathrm{Ce}(\mathrm{III}) \\
3 \mathrm{Fe}(\mathrm{II})+\mathrm{Cr}(\mathrm{VI}) \rightarrow 3 \mathrm{Fe}(\mathrm{III})+\mathrm{Cr}(\mathrm{III})
\end{gathered}
$$

The amounts of $\mathrm{Ce}(\mathrm{IV})$ and $\mathrm{Cr}(\mathrm{VI})$ consumed by the solid materials are used to quantify the reductive capacities. Measuring the reductive capacity of porous materials involves diffusion of oxidants [Ce(IV) or $\mathrm{Cr}(\mathrm{VI})]$ into the pores present in the sample materials. In the $\mathrm{Ce}(\mathrm{IV})$ method, a strong acid (10\% sulfuric acid) is used to facilitate the dissolution of the solid materials so that the oxidant can easily contact the smaller dissolving particles or the reduced solutes generated from the dissolution process. However, in the $\mathrm{Cr}(\mathrm{VI})$ method, because $10-\mathrm{mM}$ carbonate buffer solution is used to adjust the $\mathrm{pH}$ to around 7.0, there is little solid dissolution, and the particle-size reduction and the contact between the $\mathrm{Cr}(\mathrm{VI})$ oxidant and reduced species within the solids may not be complete. In this case, the PSD of the porous material is also a sensitive factor in measuring reductive capacity.

The measured PSDs of the crushed waste forms and their individual ingredients used in the reductive capacity analyses are shown in Figure 1. The PSD of fly ash (Type F) was a little bit wider than those of the cement and BFS samples, which both had a narrow range centered 
around $20 \mu \mathrm{m}$ (Figure 1a). The Cast Stone samples showed a bimodal PSD around $40 \mu \mathrm{m}$ and $400 \mu \mathrm{m}$, except for the Cast Stone prepared with S1-2M simulant (Figure 1b). The PSDs of the DuraLith dry ingredients and the DuraLith waste form prepared with the four different simulants are shown in Figures 1c and d, respectively. Metakaolinite, fumed silica, and BFS have narrow PSDs with an average particle size less than $20 \mu \mathrm{m}$, while river sand has a wide PSD with a bimodal distribution between 60 and 1,100 $\mu \mathrm{m}$ (Figure 1c). Silver zeolite has a narrow PSD and larger average particle size $(257 \mu \mathrm{m})$. However, because zeolite is a highly porous material with varying sizes of internal pores, the diffusion of oxidants, $\mathrm{Ce}(\mathrm{IV})$ or $\mathrm{Cr}(\mathrm{VI})$ inside these pores might be limited. The DuraLith and Ceramicrete waste form samples also show a narrow and unimodal PSD (Figure 1d). The PSDs of DuraLith samples made with the four simulants were similar to each other. The PSDs of the two FBSR samples and the dry ingredients used to prepare Ceramicrete are shown in Figure 1e and 1f, respectively. The two FBSR samples show very similar PSD results with an average size between $50 \mu \mathrm{m}$ and $70 \mu \mathrm{m}$. Type-C fly ash showed a wider PSD range than $\mathrm{MnO}$, but the PSD of Type-C fly ash, which ranged from 0.2 $\mu \mathrm{m}$ to $100 \mu \mathrm{m}$ (Figure 1f), is narrower than that of Type-F fly ash used in Cast Stone formulation, which ranged from $0.1 \mu \mathrm{m}$ and $1000 \mu \mathrm{m}$ (Figure 1a).

\subsection{Kinetic effects on the measured reductive capacity}

$$
\text { The effects of contact time between the oxidizing reagent and sample solids were }
$$
evaluated for BFS and Cast Stone samples using both the $\mathrm{Ce}(\mathrm{IV})$ and $\mathrm{Cr}(\mathrm{VI})$ methods to determine the optimal reaction time for measuring reductive capacity, and the results are given in Figure 2. Augus and Glasser [6] and Kaplan et al. [8] used a 1-hour reaction time to measure the reductive capacity of BFS using the $\mathrm{Ce}(\mathrm{IV})$ method. However, as shown in Figure 2, it took at 
281 least 1 or 2 days to reach reductive capacity steady state using the Ce(IV) method in our tests for

282 the BFS and Cast Stone. Roberts and Kaplan [18] also mentioned that an hour of mixing the

$283 \mathrm{Ce}(\mathrm{IV})$ solution with solid samples is sufficient time to allow $\mathrm{Ce}(\mathrm{IV})$ to diffuse completely using

284 the Augus and Glasser [6] method. However, according to our results, at least a 1- or 2-day

285 reaction time is needed to measure complete reductive capacity of all the solid materials using

286 the Ce(IV) method.

Using the $\mathrm{Cr}(\mathrm{VI})$ method, it took at least 4 days for the measured reductive capacity values to reach steady state values. Because the $\mathrm{Ce}(\mathrm{IV})$ method uses $10 \%$ sulfuric acid, and the $\mathrm{pH}$ in

$289 \mathrm{Ce}(\mathrm{IV})$ stock solution is between 0 and 1 , the $\mathrm{Ce}(\mathrm{IV})$ method measures almost total reductive 290 capacity of the solid sample that can be dissolved within a relatively short reaction period (i.e., 1 291 to 2 days). However, because the $\mathrm{Cr}(\mathrm{VI})$ method uses $10-\mathrm{mM} \mathrm{NaHCO}_{3}$ solution, and the $\mathrm{pH}$ is 292 adjusted to around 7.0, the $\mathrm{Cr}(\mathrm{VI})$ method measures primarily the surface and an unknown 293 portion of the internal particles' reductive capacity of the sample, over 4 days needed to reach 294 steady state (i.e., attain a constant value for the reductive capacity). These kinetic effects and 295 the potentially limited accessibility of the internal reductants within the solid particles to reaction 296 with the oxidizing reagent in the $\mathrm{Cr}(\mathrm{VI})$ method lead to differences between the reductive 297 capacities measured using these two methods. In secondary waste forms, because ${ }^{99} \mathrm{Tc}$ is 298 considered to be uniformly distributed and can react with reductants present in each waste form 299 following by the reaction,

$$
{ }^{99} \mathrm{Tc}(\mathrm{VII}) \mathrm{O}_{4}{ }^{-}+3 \mathrm{e}^{-}+4 \mathrm{H}^{+} \rightarrow{ }^{99} \mathrm{Tc}(\mathrm{IV}) \mathrm{O}_{2} \cdot 2 \mathrm{H}_{2} \mathrm{O}
$$

301 the reductive capacity measured by the Ce(IV) method is expected to be more useful for 302 estimating total reductive capacity of waste forms and predicting the long-term leaching of Tc 303 from secondary waste forms. 


\subsection{Reductive capacity measurements}

The reductive capacity of different secondary waste forms prepared without ${ }^{99} \mathrm{Tc}$ and

their dry ingredients was measured using two methods, and the results are given in Table 2.

307 Different waste forms with ${ }^{99}$ Tc-spiked simulants were also used to test the reductive capacity,

308 and the results are shown in Table 3. The dry blend ingredients with the largest reductive

309 capacity are BFS, tin chloride, tin fluoride, and sodium sulfide. The reductive capacity of the

310 particular BFS used in forming the Cast Stone waste forms was $799 \mathrm{meq} / \mathrm{kg}$ when the Ce(IV)

311 method was used. This value is slightly lower than the reported value of $820 \mathrm{meq} / \mathrm{kg}$ by Lukens

312 et al. [18] and Roberts and Kaplan [19] for the BFS used at Savannah River to produce Saltstone.

313 The reductive capacity of the BFS used to make Cast Stone as measured with the Cr(VI)

314 method was $346 \mathrm{meq} / \mathrm{kg}$, which is noticeably lower than the $799 \mathrm{meq} / \mathrm{kg}$ value determined with

315 the Ce(IV) method. However, the different values from these two methods are readily explained

316 by the kinetic effects of contact time and the effects of different solid dissolution rates at

317 different $\mathrm{pH}$ conditions as mentioned previously. The BFS contains both ferrous ion and sulfides

318 that are strong reductants for ${ }^{99} \mathrm{Tc}$ to enhance immobilization of ${ }^{99} \mathrm{Tc}$ inside waste forms. Both

$319 \mathrm{Fe}(\mathrm{II})$ and S(II) become reactive reductants once they dissolve, and they can effectively reduce

320 contaminants such as ${ }^{99} \mathrm{Tc}$ that may be present in the pore water within the waste form to form

321 more stable species such as reduced Tc(IV) in the secondary waste form. However, based on the

322 measurement condition, only ferrous-iron oxides present in the BFS surfaces can be measured by

323 the $\mathrm{Cr}(\mathrm{VI})$ method, while all reducing materials, including sulfur compounds and the ferrous iron

324 oxides in the BFS can be measured when the Ce(IV) method is used.

Both tin fluoride and tin chloride, used for making DuraLith and Ceramicrete waste

326 forms, respectively, show very high reductive capacities. The measured reductive capacity 
$327(8,700$ to $12,000 \mathrm{meq} / \mathrm{kg})$ for tin compounds using the two methods was similar to their

328 theoretically calculated reductive capacities, 10,549 and $12,764 \mathrm{meq} / \mathrm{kg}$ for tin fluoride and tin

329 chloride, respectively. Tin chloride, an ingredient of Ceramicrete, and tin fluoride, an ingredient

330 of DuraLith, are strong reducing agents that have a standard reduction potential, $\mathrm{E}_{\mathrm{o}}$,

$331[\mathrm{Sn}(\mathrm{IV}) / \mathrm{Sn}(\mathrm{II})]=+0.15 \mathrm{~V}[20]$. The tin (II) solids can readily oxidize to $\mathrm{Sn}(\mathrm{IV})$ upon contact

332 with oxygen or redox-sensitive constituents. When alkaline $\mathrm{pH}$ conditions are maintained and

333 the $\mathrm{Sn}(\mathrm{II})$ solution is added, $\mathrm{Sn}(\mathrm{II})$ oxide $\left(\mathrm{SnO} \cdot \mathrm{H}_{2} \mathrm{O}\right)$ precipitates and then dissolves to form

334 stannite salt $\left[\mathrm{NaSn}(\mathrm{OH})_{3}\right]$ with excess base. Most of the secondary waste forms considered in

335 this study use large amounts of caustic ingredients so that $\mathrm{Sn}$ (II) solutions can convert to the

336 stannite salt, which serves as a continuous source of reducing agent in the final solid waste form

337 and thus can behave as getter material to enhance immobilization of redox sensitive

338 contaminants in waste forms [21,22].

Sodium sulfide, an ingredient of DuraLith, can produce $\mathrm{HS}^{-}$when dissolved in water,

340 which promotes the formation of many metal sulfide precipitates. Liu et al. [23,24] also reported

341 that the reaction between sulfide and $\mathrm{TcO}_{4}{ }^{-}$in $\mathrm{pH} 9$ aqueous solution under anoxic conditions

342 produces $\mathrm{Tc}_{2} \mathrm{~S}_{7}$ precipitate according to the reaction

$$
2 \mathrm{TcO}_{4}^{-}+7 \mathrm{HS}^{-}+\mathrm{H}_{2} \mathrm{O} \rightarrow \mathrm{Tc}_{2} \mathrm{~S}_{7}+9 \mathrm{OH}^{-}
$$

344 Note that the sulfur in this compound $\left(\mathrm{Tc}_{2} \mathrm{~S}_{7}\right)$ is a mixture of polysulfides such that each sulfur is 345 not -2 charged. Also, $\mathrm{Na}_{2} \mathrm{~S}$ can oxidize to $\mathrm{Na}_{2} \mathrm{~S}_{2} \mathrm{O}_{3}$, which can react with $\mathrm{TcO}_{4}{ }^{-}$and reduce the $346 \mathrm{Tc}(\mathrm{VII})$ to form $\mathrm{TcO}_{2}$ such as the suggested reaction [19].

$$
2 \mathrm{NaTcO}_{4}+3 \mathrm{Na}_{2} \mathrm{SO}_{3}+5 \mathrm{H}_{2} \mathrm{O} \rightarrow 2 \mathrm{TcO}_{2} \cdot 2 \mathrm{H}_{2} \mathrm{O}+3 \mathrm{Na}_{2} \mathrm{SO}_{4}+2 \mathrm{NaOH}
$$

348 In addition, ${ }^{99} \mathrm{Tc}$ sequestration kinetics are faster with increasing $\mathrm{S} / \mathrm{Fe}(\mathrm{II})$ ratios between 0 and 
3490.056 and confirmed the importance of $\mathrm{FeS}$ in ${ }^{99} \mathrm{Tc}$ sequestration [25]. Therefore, $\mathrm{Na}_{2} \mathrm{~S}$ can be

350 used as an oxygen scavenger to make an anoxic condition in the secondary waste form for

351 improving ${ }^{99} \mathrm{Tc}$ retention as reduced Tc(IV) species. The measured reductive capacities of $\mathrm{Na}_{2} \mathrm{~S}$

352 varied significantly from $8,200 \mathrm{meq} / \mathrm{kg}$ to $31,000 \mathrm{meq} / \mathrm{kg}$, depending on the method used.

353 Higher reductive capacities were found for $\mathrm{Na}_{2} \mathrm{~S}$ and $\mathrm{SnF}_{2} / \mathrm{SnCl}_{2}$. The higher reducing capacities

354 for these reagents are consistent with ${ }^{99} \mathrm{Tc}$ speciation results reported by Um et al. [3], which

355 shows higher percentages of reduced ${ }^{99} \mathrm{Tc}(\mathrm{IV})$ species in DuraLith and Ceramicrete waste forms

356 based on ${ }^{99} \mathrm{Tc}$ TXANES analysis, even though their curing (aging) times after preparation were

357 relatively short compared to the curing times used for Cast Stone. Even though the BFS used to

358 make Cast Stone also showed significant reductive capacity, the magnitude of the reductive

359 capacity of the BFS material is not as large as the reductive capacity for $\mathrm{Na}_{2} \mathrm{~S}$ and $\mathrm{SnF}_{2} / \mathrm{SnCl}_{2}$ on

360 a mass basis.

Other dry ingredients had reductive capacities less than $100 \mathrm{meq} / \mathrm{kg}$, except silver zeolite

362 [i.e., 1,100 meq/kg using the $\mathrm{Cr}(\mathrm{VI})$ method] and fumed silica [i.e., $300 \mathrm{meq} / \mathrm{kg}$ using the $\mathrm{Ce}(\mathrm{IV})$

363 method]. However, the silica fume (or fumed silica) used in our work has a minor fraction of

364 elemental silicon that can produce $\mathrm{H}_{2}(\mathrm{~g})$ when it dissolves. Upon dissolution, it forms silicate

365 ions at the low $\mathrm{pH}$ value used in the $\mathrm{Ce}(\mathrm{IV})$ method, and the $\mathrm{H}_{2}(\mathrm{~g})$ oxidizes to water and

366 consumes some of the oxidant, $\mathrm{Ce}(\mathrm{IV})$. The low reductive capacity for fumed silica, $23 \mathrm{meq} / \mathrm{kg}$

367 measured with the $\mathrm{Cr}(\mathrm{VI})$ method, occurs because the $\mathrm{Cr}(\mathrm{VI})$ method is performed at a $\mathrm{pH}$ of 7 ,

368 and very little silicon is dissolved to generate $\mathrm{H}_{2}(\mathrm{~g})$. The measured reductive capacity values

369 usually showed higher values for the Ce(IV) method than for the Cr(VI) method, except for three

370 samples, sodium sulfide, silver zeolite, and tin chloride. The reason for the higher measured

371 reductive capacity for the $\mathrm{Cr}(\mathrm{VI})$ method is not clearly understood now. However, some 
372 interaction or chemical reaction between $\mathrm{Ag}$ and $\mathrm{Cr}(\mathrm{VI})$ may be possible to form very stable

373 silver chromate $\left(\mathrm{Ag}_{2} \mathrm{CrO}_{4}\right.$ with very low solubility of $1.2 \times 10^{-12} \mathrm{~mol} / \mathrm{mL}$ in $\left.\mathrm{H}_{2} \mathrm{O}\right)$, which removes

374 all the excess unused $\mathrm{Cr}(\mathrm{VI})$, thus leading to inflated reductive capacity values upon back

375 titration.

The measured reductive capacity values of the four different liquid waste simulants (see

377 Table 1) were similar, ranging from 220 to 450 meq/kg (Table 3). Simulant 4 (S4) does have a

378 slightly lower reductive capacity from the Ce(IV) method, which agrees well with the Eh results

379 for different simulants shown in Um et al. [3]. The highest Eh value was found in the S4

380 simulant $\left(\mathrm{E}_{\mathrm{h} \text { corrected }}=304.7 \mathrm{mV}\right)$ compared to others $(\mathrm{S} 1=142.6 \mathrm{mV}, \mathrm{S} 2=153.6 \mathrm{mV}$, and

$381 \mathrm{~S} 3=161.4 \mathrm{mV}$ ), which is indicative of a lower reductive capacity.

The results of measured reductive capacities for Cast Stone samples made with different

383 simulants with or without ${ }^{99} \mathrm{Tc}$ spikes are shown in Figure 3. When $\mathrm{Cr}(\mathrm{VI})$ was used as an

384 oxidant, the reductive capacity of the Cast Stone without ${ }^{99} \mathrm{Tc}$ was first measured in both oxic

385 and anoxic environments, and the results were very similar regardless of simulant types used or

386 the oxygen conditions. Effects of oxygen (an additional but uncontrolled oxidizing reagent)

387 during the measurement of the reductive capacity using the $\mathrm{Cr}(\mathrm{VI})$ method were negligible.

388 Therefore, Cast Stone samples with ${ }^{99} \mathrm{Tc}$-spiked simulants were measured without using the

389 anoxic chamber. The results showed slightly higher values than those of Cast Stone samples

390 prepared without ${ }^{99} \mathrm{Tc}$ and measured in either oxic (no chamber used) or anoxic (chamber was

391 used) environments. However, the differences in reductive capacity values among the three Cast

392 Stone samples are within their error ranges, indicating that the reductive capacities can be

393 considered to be the same. The measured reductive capacities of Cast Stone samples from the

$394 \mathrm{Ce}(\mathrm{IV})$ method also showed similar results, irrespective of different simulant types used (S1, S2, 
S3, and S4). However, higher reductive capacity values were found as the concentration of S1

(from S1-2M to S1-10M) was used to prepare the Cast Stone samples. The increasing reductive capacity measured in Cast Stone containing the increasing simulant concentrations might be related to the reactions that occur in the Cast Stone as it hydrates and transforms from slurry to a hardened paste. Also, increasing nitrite concentration with increasing simulant concentration could increase the reductive capacity in Cast Stone prepared with increasing simulant concentrations. The progressively higher salt and alkaline concentrations in the $\mathrm{S} 1$ simulant solution as it was concentrated from 2-M to 10-M Na normalized may dissolve more reducing materials present in Cast Stone dry ingredients, especially the BFS. The higher amount of dissolved reducing agents in the evolving Cast Stone pore water is then readily titrated by the acidic $\mathrm{Ce}(\mathrm{IV})$ oxidizing reagents, thus leading to the larger reduction capacity value. A similar increase in reductive capacity in the Cast Stone solids made with varying concentrations of the S1 simulant was not observed when using the $\mathrm{Cr}(\mathrm{VI})$ method. This perhaps is caused by the fact that the $\mathrm{Cr}(\mathrm{VI})$ method is performed at $\mathrm{pH}$ values near 7.0, and fewer of the dry ingredients with reductive capacity are dissolved or reacted during the hydration process.

The two FBSR solids also showed high reductive capacities when measured with the

$411 \mathrm{Ce}(\mathrm{IV})$ method (900 meq/kg to $2,800 \mathrm{meq} / \mathrm{kg})$. The reductive capacities of granular FBSR and 412 crushed FBSR with Geo-7 binder by the Ce(IV) method were much higher than the reductive 413 capacities measured by the $\mathrm{Cr}(\mathrm{VI})$ method (16 meq/ $/ \mathrm{kg}$ to $22 \mathrm{meq} / \mathrm{kg}$ ), most probably because of 414 the nature of the FBSR compounds and the different $\mathrm{pH}$ conditions between the two reducing 415 capacity measurements. The FBSR process involves slowly adding and atomizing liquid waste 416 in a bed of particles in an upward-flowing reducing-gas mixture that destroys nitrate and nitrite 417 present in the waste feed under the highly reducing environment [25]. Carbonaceous reductants, 
such as sugar and $\mathrm{CO}$, are introduced into the reducing-gas reactor as a reformer to create the

419 reducing conditions. Therefore, reduced materials, such as coal, sulfide-containing secondary

420 minerals, etc., are present in the FBSR product. Major mineral phases in the FBSR product are

421 nosean, nepheline, sodalite, and corundum [26,27]. Some of these minerals can accommodate

422 sulfate or sulfide, depending on the redox environment in the steam reforming process [26].

423 Organic substances in the FBSR product generate low reductive capacity values when measured

424 with the $\mathrm{Cr}(\mathrm{VI})$ method because the dissolution rate of these organics is very slow in the neutral

$425 \mathrm{pH}$ conditions used in the $\mathrm{Cr}(\mathrm{VI})$ method [7]. With 10\% sulfuric acid used in the Ce(IV) method,

426 most of the organic and inorganic materials present in FBSR are completely dissolved. Also, the

427 FBSR major minerals are feldspathoids and zeolite minerals, which have highly porous cage

428 structures. At neutral $\mathrm{pH}$ conditions, these minerals are considered to be stable so that there is

429 little reaction when the $\mathrm{Cr}(\mathrm{VI})$ method is used to measure their reductive capacities. In the

$430 \mathrm{Ce}(\mathrm{IV})$ method performed at very low $\mathrm{pH}$ levels, these zeolite minerals were partially dissolved

431 and could be inflating the measured reductive capacities. Finally, DuraLith and Ceramicrete

432 waste form samples showed higher reductive capacities than the Cast Stone samples because of

433 the higher masses of highly reactive reductants used to prepare these waste forms.

\subsection{Prediction of Cast Stone reductive capacity}

The measured reductive capacities of Cast Stone samples prepared without ${ }^{99} \mathrm{Tc}$ were compared with the reductive capacities estimated by summing values of the independently

438 measured reductive capacity for each dry ingredient multiplied by its weight percent in the Cast

439 Stone formulation. The comparison is shown in Figure 4, where a little bit higher reductive 440 capacity is measured in the cured Cast Stone solids than is calculated from the sum of the 
441 reductive capacities of the individual dry ingredients, which suggests that increase in the

442 reductive capacity originated from the curing (or aging) process in Cast Stone. The time-

443 dependent nature of the Cast Stone reductive capacity could be the cause of the varying

444 contributions of $\mathrm{Tc}(\mathrm{IV}) / \mathrm{Tc}(\mathrm{VII})$ species as a function of different aging times (e.g., contribution

445 of Tc(IV) increased in the Cast Stone as the aging process increased) observed and discussed in

446 Um et al. [3]. However, the predictor relationship shown in Figure 4 can be useful to estimate at

447 least the initial reductive capacity of various waste forms based on the measured reductive

448 capacities of their individual dry ingredients.

\section{Conclusions}

Our main goal was to evaluate the methods, compare the results and discuss reasons for

452 observed differences in measured reduction capacities. The reductive capacities of dry

453 ingredients used to prepare each waste form and the four waste forms - Cast Stone, DuraLith,

454 FBSR, and Ceramicrete - prepared using different liquid waste simulants with or without ${ }^{99} \mathrm{Tc}$

455 were measured with two methods that use different oxidants [i.e., $\mathrm{Ce}(\mathrm{IV})$ and $\mathrm{Cr}(\mathrm{VI})$ ]. $\mathrm{The}$

456 measured reductive capacity values were generally higher when using the Ce(IV) method

457 compared to those obtained when the $\mathrm{Cr}(\mathrm{VI})$ method was used. The difference is probably

458 caused by the different $\mathrm{pH}$ conditions used in these two methods. The materials with the highest

459 measured reductive capacities are $\mathrm{BFS}$, sodium sulfide, and $\mathrm{SnF}_{2} / \mathrm{SnCl}_{2}$ used as starting

460 ingredients to make various waste forms. Sodium sulfide and $\mathrm{SnF}_{2} / \mathrm{SnCl}_{2}$ exhibit significantly

461 higher reductive capacities per gram of sample compared to all other ingredients. The reductive

462 capacities for the four different simulants at 2-M Na concentrations were similar, but again, the 
463 values differed depending on method used. The simulant S4 did exhibit a slightly lower

464 reductive capacity value compared to the other three simulants (S1, S2, and S3). However, the

465 minor differences in reductive capacity for the various $2 \mathrm{M}$ Na simulants did not contribute any

466 significant differences in the overall reductive capacity measured in the final waste forms

467 because the volume or weight percent of the $2 \mathrm{M}$ Na simulants was not high $(<10 \mathrm{wt} \%)$ in the

468 final waste forms. The overall reductive capacities of the different waste forms were also not

469 influenced by whether the simulant did or did not contain ${ }^{99} \mathrm{Tc}$ as would be expected given the

470 low Tc concentration $\left(\sim 1 \times 10^{-3}\right.$ to $<8 \times 10^{-6} \mathrm{M}$ depending on simulant). The granular FBSR

471 sample exhibited a larger reductive capacity than the FBSR- Geo-7 waste form. This finding

472 suggests that the Geo-7 binder itself does not have significant reductive properties and simply

473 diluted the reductive properties of the granular FBSR product, or alternatively the Geo-7 coating

474 over the FBSR grains partially protected the grains long enough in the acidic $\mathrm{Ce}(\mathrm{IV})$ slurry that

475 the total reductive capacity of the FBSR product was not measured. The DuraLith and

476 Ceramicrete waste forms showed significantly larger reductive capacities than Cast Stone

477 because of the large amounts of the strong reductants sodium sulfide and $\mathrm{SnF}_{2} / \mathrm{SnCl}_{2}$ used in

478 preparing these two waste forms. Based on the measured reductive capacity values for most of

479 the materials investigated, including individual dry ingredients and final waste forms using the

480 two different methods, the reaction time and the solution $\mathrm{pH}$ condition are the critical parameters

481 that influence the measured reductive capacity. 
487 Washington for the project funding and programmatic guidance. We also acknowledge Steven

488 Baum, Keith Geiszler, Cristian Iovin, Igor Kutnyakov, and Dennese Smith in the Geosciences 489 group at PNNL for their analytical and laboratory support. Additional support was provided by

490 WCU (World Class University) and BK21+ programs at the Division of Advanced Nuclear 491 Engineering (DANE) in POSTECH through the National Research Foundation of Korea funded 492 by the Ministry of Education, Science and Technology (R31-30005). Pacific Northwest National 493 Laboratory is a multi-program national laboratory operated by Battelle Memorial Institute for the 494 U.S. Department of Energy under contract DE-AC06-76RLO 1830.

\section{References}

497 [1] J.G. Darab, P.A. Smith, Chemistry of Materials 8(5) (1996) 1004.

498 [2] D.H. Bacon, B.P. McGrail, Pacific Northwest National Laboratory (2001) PNNL-13369.

499 [3] W. Um, M.E. Valenta, C.W. Chung, J. Yang, M.H. Engelhard, R.J. Serne, K.E. Parker, G.

500 Wang, K.J. Cantrell, J.H. Westsik Jr., Pacific Northwest National Laboratory (2011) PNNL50120753.

502 [4] W. Um, H.-S. Chang, J.P. Icenhower, W.W. Lukens, R.J. Serne, N.P. Qafoku, J.H. Westsik, 503 E.C. Buck, S.C. Smith, Environmental Science \&Technology 45 (2011) 4904.

504 [5] W. Um, H.-S. Chang, J.P. Icenhower, W.W. Lukens, R.J. Serne, N.P. Qafoku, R.K.

505 Kukkadapu, J.H. Westsik Jr., Journal of Nuclear Materials 429 (2012) 201. 
[6] M.J. Angus, F.P. Glasser, Materials Research Society Symposium Proceedings 50 (1985) 547.

507 [7] W. Lee, B. Batchelor, M.A. Schlautman, Environmental Technology 21(8) (2000) 953.

508 [8] D.I. Kaplan, T. Hang, S.E. Aleman, Westinghouse Savannah River Company (2005) WSRC509 RP-2005-01674 Rev. 0.

510 [9] E.M. Pierce, W. Um, K.J. Cantrell, M.M. Valenta, J.H. Westsik, Jr., R.J. Serne, K.E. Parker, 511 Pacific Northwest National Laboratory (2010) PNNL-19505.

512 [10] S.K. Sundaram, J. Chun, W. Um, K.E. Parker, C-W. Chung, J.H. Westsik, Jr., M.E. Valenta, 513 M.L. Kimura, S.G. Pitman, C.A. Burns, Pacific Northwest National Laboratory (2011) PNNL51420159.

515 [11] L.L. Lockrem, Fluor Hanford (2005) RPP-RPT-26742, Rev. 0.

516 [12] L.L. Lockrem, G.A. Cooke, B.A. Clark, R. Westburg, CH2M Hill Hanford Group, Inc. 517 (2008) RPP-RPT-26725, Rev. 0-A.

518 [13] D.S. Perera, Z. Aly, E.R. Vance, M. Mizumo, Journal of the American Ceramic Society $519 \quad 88(9)(2005) 2586$.

520 [14] R.L. Russell, M.J. Schweiger, J.H. Westsik Jr., P.R. Hrma, D.E. Smith, A.B. Gallegos, M.R. 521 Telander, S.G. Pitman, Pacific Northwest National Laboratory (2006) PNNL-16052, Rev.1.

522 [15] R.P. Pires, J.H. Westsik Jr., R.J. Serne, S.V. Mattigod, E.C. Golovich, M.M. Valenta, K.E. 523 Parker, Pacific Northwest National Laboratory (2011) PNNL-20551. 
524 [16] D. Singh, A.S. Wagh, J.C. Cunnane, J.L. Mayberry, Journal of Environmental Science and $525 \quad$ Health Part A 32 (1997) 527.

526 [17] A.S. Wagh, Chemically Bonded Phosphate Ceramics: Twenty-First Century Materials with 527 Diverse Applications. (2004).

528 [18] K.A. Roberts, D.I. Kaplan, Savannah River National Laboratory (2009) SRNL-STI-2009-

52900637 Rev 0.

530 [19] W.W. Lukens, J.J. Bucher, D.K. Shuh, N.M. Edelstein, Environmental Science 531 \&Technology 39(20) (2005) 8064.

532 [20] R.H. Petrucci, W.S. Harwood, G.E. Herring, J. Madura, General Chemistry: Principles and 533 Modern Applications. 9th ed. (2007).

534 [21] S.V. Mattigod, G.E. Fryxell, R.J. Serne, K.E. Parker, Radiochimica Acta 91(9) (2003) 539.

535 [22] J.L. Krumhansl, J.D. Pless, J.B. Chwirka, K.C. Holt, Sandia National Laboratory (2006)

536 SAND2006-3869.

537 [23] Y. Liu, J. Terry, S.S. Jurisson, Radiochimica Acta 96 (2008) 823.

538 [24] Y. Liu, J. Terry, S.S. Jurisson, Radiochimica Acta 97 (2009) 33.

539 [25] A.L. Olson, N.R. Soelberg, D.W. Marshall, G.L. Anderson, Idaho National Engineering and 540 Environmental Laboratory (2004) INEEL/EXT-04-02564.

541 [26] C.M. Jantzen, Westinghouse Savannah River Company (2003) WSRC-MS-2003-00595 542 Rev. 0. 
543 [27] C.M. Jantzen, J.C. Marra, J.M. Pareizs, Savannah River National Laboratory (2004) SRNL544 ITB-2004-0004.

545 [28] D. Fan, R.P. Anitori, B.M. Tebo, P.G. Tratnyek, Environmental Science \&Technology 47

$546 \quad$ (2013) 5302.

547

548 
Tables and Figures.

550

551

552

553

554

555

556

557

558

559

560

561

562

563

564

565

566

567

568
Table 1. Composition of WTP secondary waste simulants

Table 2. Reductive capacities of secondary waste forms without Tc and their ingredients

Table 3. Reductive capacities of ${ }^{99} \mathrm{Tc}$ loaded secondary waste forms

Figure 1. Measured particle size distributions (PSDs) of dry Ingredients used for making Cast

Stone (a), Cast Stones (b), dry Ingredients of DuraLith (c), Geopolymers (d), FBSR Waste Forms

(e), and dry Ingredients used for Ceramicrete (f).

Figure 2. Effect of reaction time for the measurement of reductive capacity

Figure 3. Measured reductive capacity of Cast Stone samples without ${ }^{99} \mathrm{Tc}$ and ${ }^{99} \mathrm{Tc}-$ loaded

Cast Stone samples using the $\mathrm{Ce}(\mathrm{IV})$ and $\mathrm{Cr}(\mathrm{VI})$ methods. For the $\mathrm{Cr}(\mathrm{VI})$ method, the reductive

capacity was measured under both anoxic and oxic environments for Cast Stone samples

prepared without ${ }^{99} \mathrm{Tc}$. Other reductive capacities were conducted only in an aerobic

environment.

Figure 4. Relationship between estimated and measured Cast Stone reductive capacities. The

measured values are the symbols, and the dotted line indicates a 1:1 correlation between

measured and calculated reductive capacity values. 
Table 1. Composition of WTP secondary waste simulants

\begin{tabular}{|c|c|c|c|c|c|}
\hline $\begin{array}{c}\text { Element } \\
\text { (mole/liter) }\end{array}$ & $\begin{array}{c}\text { S1 } \\
\text { Caustic } \\
\text { Scrubber } \\
\text { Median }\end{array}$ & $\begin{array}{c}\text { S2 } \\
\text { Statistical - } \\
\text { Cluster 1 } \\
\text { 3/16/2038 }\end{array}$ & $\begin{array}{c}\text { S3 } \\
\text { Statistical - } \\
\text { Cluster 2 } \\
\text { 05/28/2024 }\end{array}$ & $\begin{array}{c}\text { S4 } \\
\text { Caustic } \\
\text { Scrubber/ } \\
\text { 10\% of SBS } \\
\text { Blend }\end{array}$ & $\begin{array}{l}\text { Phase } 1 \\
\text { Simulant }\end{array}$ \\
\hline $\mathrm{Na}$ & 2 & 2 & 2 & 2 & 2 \\
\hline $\mathrm{Al}(\mathrm{OH})_{3}$ & $1.88 \mathrm{E}-01$ & $2.28 \mathrm{E}-01$ & $1.84 \mathrm{E}-01$ & $8.48 \mathrm{E}-02$ & 0.23 \\
\hline $\mathrm{Si}$ & $3.76 \mathrm{E}-03$ & $4.08 \mathrm{E}-03$ & $1.55 \mathrm{E}-03$ & 2.78E-02 & - \\
\hline K & $1.16 \mathrm{E}-03$ & $1.30 \mathrm{E}-03$ & $4.36 \mathrm{E}-03$ & $5.74 \mathrm{E}-02$ & - \\
\hline $\mathrm{NH}_{4}{ }^{+}$(total) & --- & --- & --- & $8.82 \mathrm{E}-01$ & - \\
\hline $\mathrm{OH}^{-}$ & 7.96E-01 & 8.70E-01 & 4.90E-01 & 2.04E-08 & 1.2 \\
\hline $\mathrm{NO}_{3}{ }^{-}$ & $6.56 \mathrm{E}-01$ & $3.80 \mathrm{E}-01$ & 7.94E-01 & $2.26 \mathrm{E}+00$ & 0.69 \\
\hline $\mathrm{CO}_{3}{ }^{2-}$ & $4.56 \mathrm{E}-02$ & $9.32 \mathrm{E}-02$ & $7.88 \mathrm{E}-02$ & $2.08 \mathrm{E}-02$ & $1.5 \mathrm{E}-6$ \\
\hline $\mathrm{Cl}^{-}$ & $4.50 \mathrm{E}-02$ & 4.34E-02 & $5.82 \mathrm{E}-02$ & $2.08 \mathrm{E}-02$ & - \\
\hline $\mathrm{NO}_{2}^{-}$ & $2.40 \mathrm{E}-02$ & $2.10 \mathrm{E}-02$ & $7.66 \mathrm{E}-02$ & 8.62E-02 & - \\
\hline $\mathrm{PO}_{4}^{-3}$ & $1.37 \mathrm{E}-02$ & $9.70 \mathrm{E}-03$ & $1.21 \mathrm{E}-02$ & $1.02 \mathrm{E}-02$ & $1.7 \mathrm{E}-2$ \\
\hline $\mathrm{SO}_{4}^{-2}$ & $8.82 \mathrm{E}-03$ & $1.16 \mathrm{E}-02$ & 1.03E-02 & 8.72E-02 & $9.7 \mathrm{E}-3$ \\
\hline $\mathrm{F}^{-}$ & $1.11 \mathrm{E}-03$ & 7.50E-04 & 8.84E-04 & 2.04E-08 & - \\
\hline $\mathrm{Cr}$ & $4.06 \mathrm{E}-04$ & $4.06 \mathrm{E}-04$ & $4.06 \mathrm{E}-04$ & $2.18 \mathrm{E}-03$ & $\begin{array}{c}8.43 \mathrm{E}-3 \\
(1 \times)\end{array}$ \\
\hline $\mathrm{Ag}$ & $1.25 \mathrm{E}-05$ & $1.25 \mathrm{E}-05$ & $1.25 \mathrm{E}-05$ & $4.70 \mathrm{E}-05$ & $\begin{array}{c}2.5 \mathrm{E}-4 \\
(100 \times)^{(\mathrm{a})}\end{array}$ \\
\hline As & 6.96E-05 & $6.96 \mathrm{E}-05$ & $6.96 \mathrm{E}-05$ & $3.22 \mathrm{E}-05$ & - \\
\hline $\mathrm{Cd}$ & $3.14 \mathrm{E}-06$ & $3.14 \mathrm{E}-06$ & $3.14 \mathrm{E}-06$ & 4.32E-05 & $\begin{array}{l}5.0 \mathrm{E}-5 \\
(100 \times)\end{array}$ \\
\hline $\mathrm{Hg}$ & $2.26 \mathrm{E}-05$ & $2.26 \mathrm{E}-05$ & $1.13 \mathrm{E}-05$ & $1.06 \mathrm{E}-05$ & $3.3 \mathrm{E}-5(1 \times)$ \\
\hline $\mathrm{Pb}$ & $1.80 \mathrm{E}-05$ & $1.80 \mathrm{E}-05$ & $1.80 \mathrm{E}-05$ & $1.66 \mathrm{E}-05$ & $\begin{array}{l}7.9 \mathrm{E}-4 \\
(100 \times)\end{array}$ \\
\hline $\mathrm{Tc}$ & $3.62 \mathrm{E}-05$ & $3.62 \mathrm{E}-05$ & $3.62 \mathrm{E}-05$ & $1.12 \mathrm{E}-03$ & \\
\hline${ }^{99} \mathrm{Tc}(\mathrm{Ci} /$ Liter $)$ & $6.05 \mathrm{E}-05$ & $6.10 \mathrm{E}-05$ & $6.10 \mathrm{E}-05$ & $1.88 \mathrm{E}-03$ & 1.3E-5 Ci/L \\
\hline I & $9.24 \mathrm{E}-06$ & $9.24 \mathrm{E}-06$ & $9.24 \mathrm{E}-06$ & $1.26 \mathrm{E}-04$ & $2.9 \mathrm{E}-6$ \\
\hline${ }^{129} \mathrm{I}$ (Ci/Liter) & $1.91 \mathrm{E}-07$ & $1.91 \mathrm{E}-07$ & $1.91 \mathrm{E}-07$ & $2.60 \mathrm{E}-06$ & \\
\hline $\begin{array}{c}\mathrm{TOC}^{(\mathrm{b})} \text { (as } \\
\text { oxalate) }\end{array}$ & $1.88 \mathrm{E}-01$ & $2.28 \mathrm{E}-01$ & $1.84 \mathrm{E}-01$ & $8.48 \mathrm{E}-02$ & 0.23 \\
\hline
\end{tabular}


Table 2. Reductive capacities of secondary waste forms without Tc and their ingredients

\begin{tabular}{|c|c|c|c|}
\hline Materials & Simulants & $\begin{array}{c}\text { Reductive Capacity } \\
\text { (Ce(IV) method) } \\
(\mathrm{meq} / \mathrm{kg})\end{array}$ & $\begin{array}{c}\text { Reductive Capacity } \\
\text { (Cr(VI) method) } \\
(\mathrm{meq} / \mathrm{kg})\end{array}$ \\
\hline \multicolumn{4}{|l|}{ Cast Stone Ingredients } \\
\hline Blast Furnace Slag & & $798.7 \pm 14.2$ & $345.6 \pm 21.9$ \\
\hline Fly Ash (Type F) & & $77.3 \pm 1.3$ & $2.0 \pm 0.4$ \\
\hline Portland Cement & & $79.0 \pm 33.0$ & $35.2 \pm 2.9$ \\
\hline \multicolumn{4}{|l|}{ Cast Stone Variants } \\
\hline Cast Stone S1-2M & $\mathrm{S} 1$ (2-M Na) & $398.7 \pm 3.2$ & $185.4 \pm 7.6$ \\
\hline Cast Stone S1-4M & S1 (4-M Na) & $442.0 \pm 3.4$ & $181.9 \pm 8.2$ \\
\hline Cast Stone S1-6M & S1 (6-M Na) & $485.3 \pm 5.7$ & $192.8 \pm 1.7$ \\
\hline Cast Stone S1-8M & S1 (8-M Na) & $540.0 \pm 1.9$ & $189.1 \pm 1.4$ \\
\hline Cast Stone S1-10M & S1 (10-M Na) & $595.6 \pm 2.0$ & $179.0 \pm 2.8$ \\
\hline Cast Stone S2-2M & S2 (2-M Na) & $401.7 \pm 4.6$ & $184.4 \pm 3.9$ \\
\hline Cast Stone S3-2M & S3 (2-M Na) & $449.6 \pm 1.4$ & $199.8 \pm 7.3$ \\
\hline Cast Stone S4-2M & S4 (2-M Na) & $461.1 \pm 12.6$ & $212.4 \pm 2.0$ \\
\hline \multicolumn{4}{|l|}{ DuraLith Ingredients } \\
\hline Silica Fume & & $300.6 \pm 6.7$ & $22.5 \pm 2.6$ \\
\hline Meta-Kaolinite & & $0.4 \pm 0.0$ & $0.3 \pm 0.2$ \\
\hline River Sand & & $1.6 \pm 1.2$ & $1.0 \pm 0.8$ \\
\hline Silver Zeolite & & $47.7 \pm 6.2$ & $1,129.0 \pm 52.4$ \\
\hline Blast Furnace Slag & & $798.7 \pm 14.2$ & $435.9 \pm 8.1$ \\
\hline Sodium Sulfide Hydrate & & $8,210.8 \pm 287.9$ & $31,049.9 \pm 1158$ \\
\hline Tin Fluoride & & $12,194.3 \pm 120.3$ & $8,652.1 \pm 715.5$ \\
\hline \multicolumn{4}{|l|}{ DuraLith Geopolymer } \\
\hline DuraLith S1-2M & $\mathrm{S} 1(2 \mathrm{M} \mathrm{Na})$ & $456.9 \pm 3.1$ & $128.2 \pm 2.4$ \\
\hline DuraLith S2-2M & $\mathrm{S} 2(2 \mathrm{M} \mathrm{Na})$ & $458.2 \pm 3.1$ & $114.3 \pm 0.7$ \\
\hline DuraLith S3-2M & S3 (2M Na) & $464.9 \pm 2.9$ & $134.4 \pm 2.5$ \\
\hline DuraLith S4-2M & $\mathrm{S} 4(2 \mathrm{M} \mathrm{Na})$ & $411.7 \pm 2.6$ & $115.6 \pm 0.6$ \\
\hline \multicolumn{4}{|l|}{ Ceramicrete Ingredients } \\
\hline Tin Chloride & & $10,038.8 \pm 98.3$ & $11,315.2 \pm 613.2$ \\
\hline Fly ash (Type C) & & $84.1 \pm 4.1$ & $27.0 \pm 1.7$ \\
\hline Silver Zeolite & & $47.7 \pm 6.2$ & $1,129.0 \pm 52.4$ \\
\hline $\mathrm{MgO}$ & & $281.6 \pm 0.0$ & $199.5 \pm 12.2$ \\
\hline $\mathrm{KH}_{2} \mathrm{PO}_{4}$ & & $18.1 \pm 0.7$ & $10.6 \pm 0.7$ \\
\hline \multicolumn{4}{|l|}{ FBSR } \\
\hline FBSR Powder & & $2,823.2 \pm 45.0$ & $21.7 \pm 2.5$ \\
\hline FBSR Milled Powder & & $914.9 \pm 8.1$ & $16.4 \pm 5.4$ \\
\hline \multicolumn{4}{|l|}{ Simulants } \\
\hline Simulant 1 & $\mathrm{~S} 1$ (2M Na) & $366.4 \pm 19.8$ & $218.2 \pm 6.0$ \\
\hline Simulant 2 & $\mathrm{~S} 2(2 \mathrm{M} \mathrm{Na})$ & $450.0 \pm 1.2$ & $229.5 \pm 3.3$ \\
\hline Simulant 3 & $\mathrm{~S} 3(2 \mathrm{M} \mathrm{Na})$ & $441.9 \pm 8.1$ & $325.6 \pm 13.4$ \\
\hline Simulant 4 & $\mathrm{~S} 4(2 \mathrm{M} \mathrm{Na})$ & $281.1 \pm 2.3$ & $289.8 \pm 4.3$ \\
\hline
\end{tabular}


Table 3. Reductive capacities of ${ }^{99} \mathrm{Tc}$ loaded secondary waste forms

\begin{tabular}{|c|c|c|c|}
\hline Materials & Simulants & $\begin{array}{c}\text { Reductive Capacity } \\
\text { (Ce(IV) method) } \\
\text { (meq/kg) }\end{array}$ & $\begin{array}{c}\text { Reductive Capacity } \\
\text { (Cr(VI) method) } \\
\text { (meq/kg) }\end{array}$ \\
\hline \multicolumn{4}{|l|}{${ }^{99}$ Tc-Loaded Cast Stone } \\
\hline${ }^{99}$ Tc-Loaded Cast Stone S1-2M & $\mathrm{S} 1(2-\mathrm{M} \mathrm{Na})$ & $379.4 \pm 5.6$ & $212.5 \pm 7.7$ \\
\hline${ }^{99} \mathrm{Tc}-$ Loaded Cast Stone S1-4M & $\mathrm{S} 1$ (4-M Na) & $445.3 \pm 13.0$ & $209.6 \pm 6.5$ \\
\hline${ }^{99}$ Tc-Loaded Cast Stone S1-6M & $\mathrm{S} 1$ (6-M Na) & $495.6 \pm 2.0$ & $215.7 \pm 13.1$ \\
\hline${ }^{99}$ Tc-Loaded Cast Stone S1-8M & $\mathrm{S} 1(8-\mathrm{M} \mathrm{Na})$ & $556.7 \pm 3.2$ & $219.3 \pm 9.9$ \\
\hline${ }^{99}$ Tc-Loaded Cast Stone S1-10M & S1 (10-M Na) & $528.3 \pm 2.6$ & $205.0 \pm 14.8$ \\
\hline${ }^{99}$ Tc-Loaded Cast Stone S2-2M & S2 (2-M Na) & $402.5 \pm 3.3$ & $203.7 \pm 25.1$ \\
\hline${ }^{99}$ Tc-Loaded Cast Stone S3-2M & S3 (2-M Na) & $500.4 \pm 5.2$ & $211.1 \pm 13.6$ \\
\hline${ }^{99}$ Tc-Loaded Cast Stone S4-2M & $\mathrm{S} 4(2-\mathrm{M} \mathrm{Na})$ & $423.7 \pm 8.6$ & $204.0 \pm 7.3$ \\
\hline \multicolumn{4}{|l|}{${ }^{99}$ Tc-Loaded DuraLith } \\
\hline${ }^{99}$ Tc-Loaded DuraLith S1-2M & $\mathrm{S} 1(2-\mathrm{M} \mathrm{Na})$ & $581.9 \pm 10.5$ & $116.9 \pm 12.9$ \\
\hline${ }^{99}$ Tc-Loaded DuraLith S2-2M & $\mathrm{S} 2(2-\mathrm{M} \mathrm{Na})$ & $536.6 \pm 8.9$ & $105.1 \pm 7.6$ \\
\hline${ }^{99}$ Tc-Loaded DuraLith S3-2M & $\mathrm{S} 3(2-\mathrm{M} \mathrm{Na})$ & $561.9 \pm 17.9$ & $131.2 \pm 5.7$ \\
\hline${ }^{99}$ Tc-Loaded DuraLith S4-2M & $\mathrm{S} 4(2-\mathrm{M} \mathrm{Na})$ & $540.0 \pm 18.1$ & $126.5 \pm 5.2$ \\
\hline \multicolumn{4}{|l|}{${ }^{99}$ Tc-Loaded Ceramicrete } \\
\hline${ }^{99}$ Tc-Loaded Ceramicrete S1-2M & $\mathrm{S} 1(2-\mathrm{M} \mathrm{Na})$ & $943.5 \pm 2.4$ & $167.6 \pm 2.8$ \\
\hline
\end{tabular}



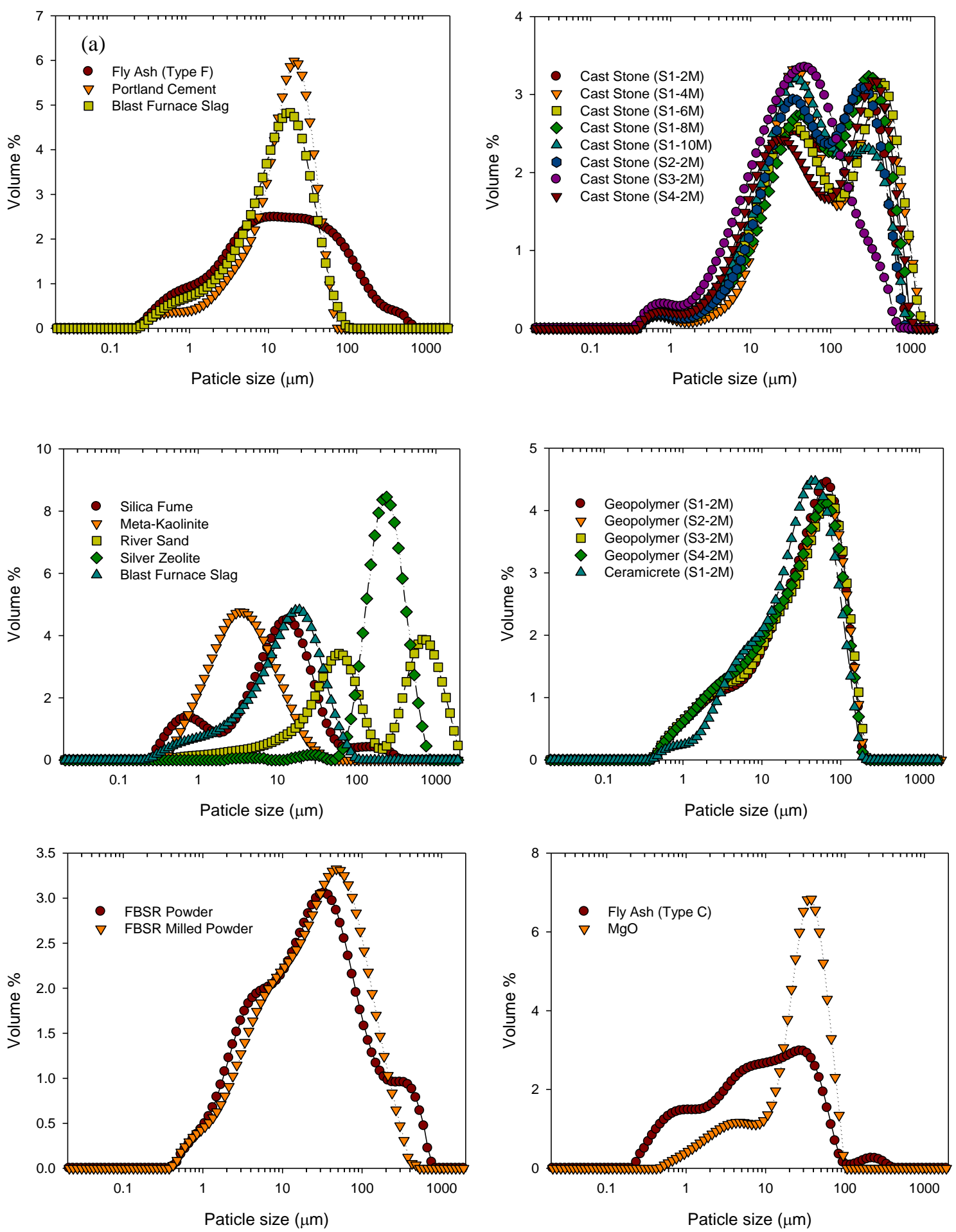

Figure 1. Measured particle size distributions (PSDs) of dry Ingredients used for making Cast

589 Stone (a), Cast Stones (b), dry Ingredients of DuraLith (c), Geopolymers (d), FBSR Waste Forms (e), and dry Ingredients used for Ceramicrete (f). 
591

592

593

594

595

596

597

598

599

600

601

602

603

604

605

606

607

608

609

610

611

612

613

614

615

616

617

618

619

Figure 2.

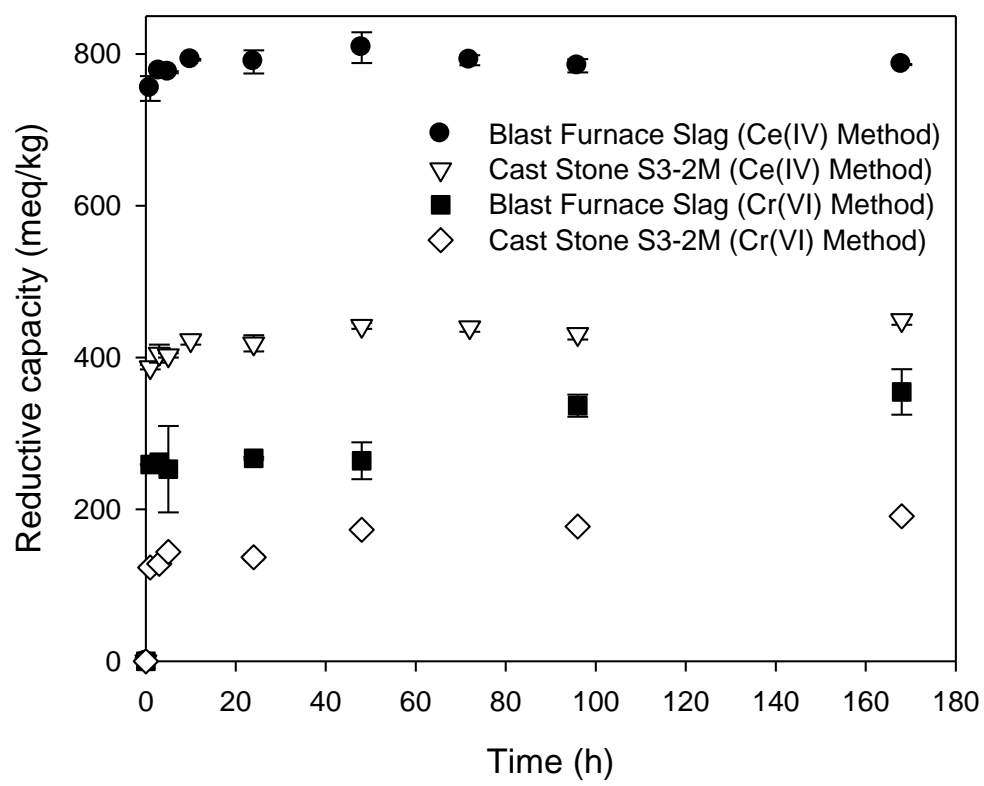

Figure 2. Effect of reaction time for the measurement of reductive capacity 
Figure 3.

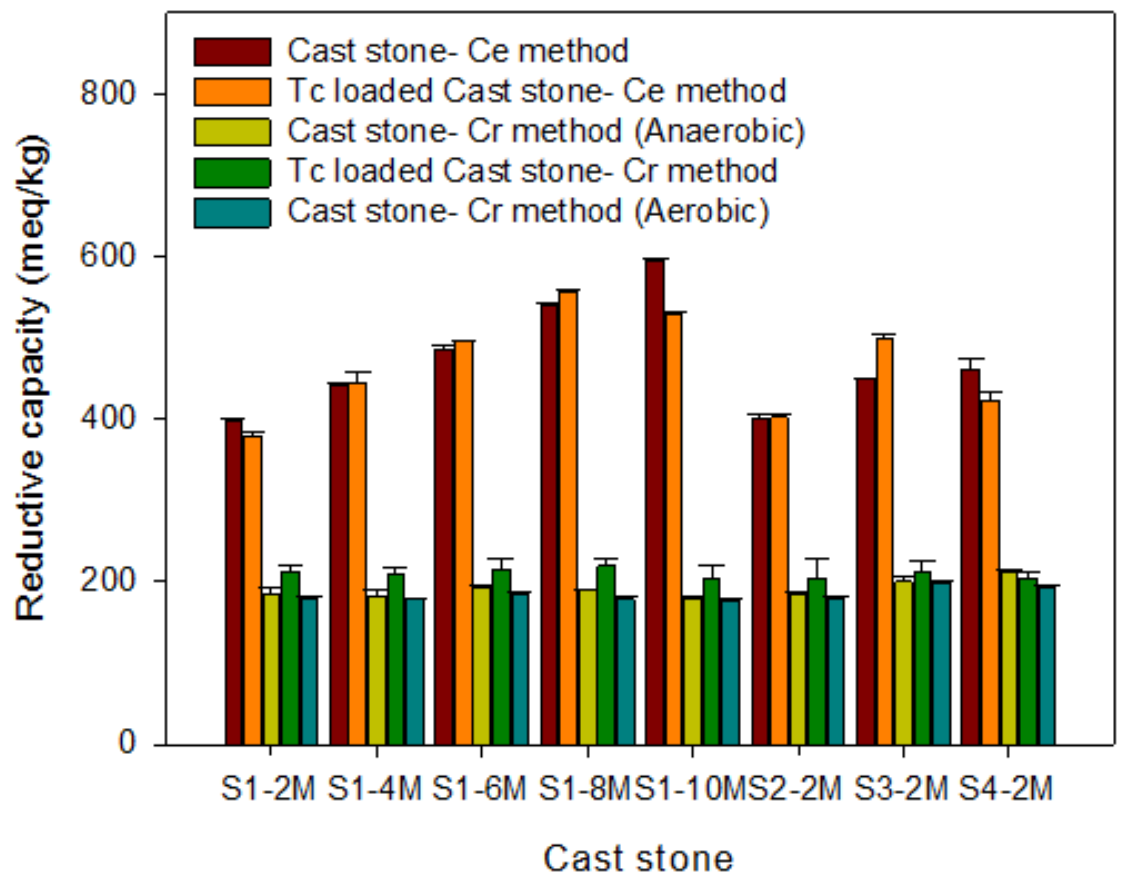

Figure 3. Measured reductive capacity of Cast Stone samples without ${ }^{99} \mathrm{Tc}$ and ${ }^{99} \mathrm{Tc}-$ loaded capacity was measured under both anoxic and oxic environments for Cast Stone samples prepared without ${ }^{99} \mathrm{Tc}$. Other reductive capacities were conducted only in an aerobic environment. 
636

637

638

639

640

641

642

643

644

645
Figure 4.

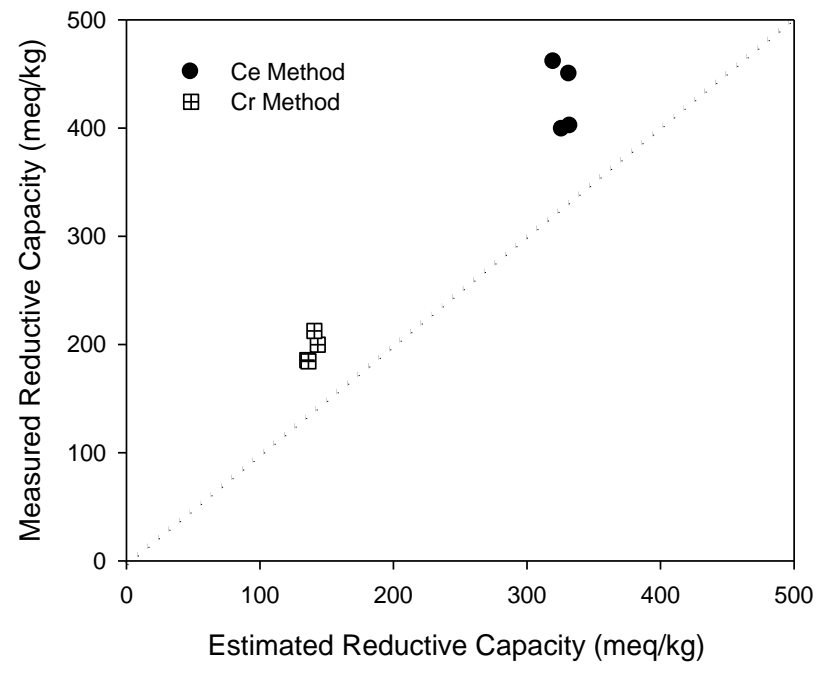

Figure 4. Relationship between estimated and measured Cast Stone reductive capacities. The measured values are the symbols, and the dotted line indicates a 1:1 correlation between measured and calculated reductive capacity values. 